BULLETIN Bulletin hispanique

HISPANIQUE Université Michel de Montaigne Bordeaux

$115-2$ | 2013

Les traductions vieillissent-elles ?

Mario Vargas Llosa, La civilización del espectáculo

Alfaguara, Madrid, 2012

Tatiana Alvarado Teodorika

\title{
OpenEdition
}

Journals

Edición electrónica

URL: http://journals.openedition.org/bulletinhispanique/2951

DOI: 10.4000/bulletinhispanique.2951

ISSN: 1775-3821

Editor

Presses universitaires de Bordeaux

Edición impresa

Fecha de publicación: 28 diciembre 2013

Paginación: 786-791

ISBN: 978-2-86781-908-7

ISSN: 0007-4640

Referencia electrónica

Tatiana Alvarado Teodorika, « Mario Vargas Llosa, La civilización del espectáculo », Bulletin hispanique [En línea], 115-2 | 2013, Publicado el 14 febrero 2014, consultado el 21 diciembre 2020. URL : http:// journals.openedition.org/bulletinhispanique/2951; DOI : https://doi.org/10.4000/bulletinhispanique. 2951

Este documento fue generado automáticamente el 21 diciembre 2020.

Tous droits réservés 


\section{Mario Vargas Llosa, La civilización del espectáculo}

Alfaguara, Madrid, 2012

Tatiana Alvarado Teodorika

\section{REFERENCIA}

Mario Vargas Llosa, La civilización del espectáculo. Madrid, Alfaguara, 2012, 227 pp. ISBN

978-84-204-1148-4.

1 Mario Vargas Llosa inicia su ensayo precisando que lo que busca es dejar constancia de la metamorfosis de contenido que ha sufrido (y aquí la palabra la empleo a propósito) el término cultura. Hace una revisión de ensayos de las últimas décadas en lo que se debate precisamente sobre la crisis que atraviesa la cultura de nuestra época, y empieza con el Notes Towards the Definition of Culture de T. S. Eliot (de 1948), en el que advierte el anuncio de los tiempos que vivimos nosotros hoy...

Expone el modelo ideal de Eliot de una cultura estructurada en tres instancias (individuo, grupo élite y la sociedad en su conjunto), desarrollándolo en algunos puntos y argumentándolo (la alta cultura como patrimonio de una élite que al buscar democratizar sólo puede empobrecerse y hacerse cada vez más superficial; la familia y la Iglesia como transmisores de cultura...). Pasa a referirse al ensayo contestatario de 1971 en el que G. Steiner responde a Eliot en su In Bluebird's Castle. Some Notes Towards the Redefinition of Culture, escandalizado por que éste omitiera en su trabajo una reflexión sobre el Holocausto, pues poco hacía que la Segunda Guerra Mundial había acabado. A través de sus reflexiones Steiner pretende colmar el vacío del estudio de Eliot, de modo que Vargas Llosa sintetiza su análisis para cumplir con el panorama amplio que desea presentar. Steiner afirma «Me parece irresponsable toda teoría de la cultura [...] que no tenga como eje la consideración de los modos de terror que acarrearon la muerte por obra de la guerra, del hambre y de las matanzas deliberadas de unos setenta millones de seres humanos muertos en Europa y Rusia entre el 
comienzo de la Primera Guerra Mundial y el fin de la Segunda». Y refiriéndose a la religión, considera que todo gran arte nace de una aspiración a la trascendencia, noción ligada no sólo a la religión sino a la idea de un dios único, idea que concibe el pueblo judío y que viene a ser remplazada por la del dios mosaico del cristianismo, que mezcla ideales monoteístas y prácticas politeístas. El dios único cae víctima de los filósofos de la Ilustración, convencidos de que una cultura laica acabaría con la violencia y las matanzas; pero el mundo sin dios vino a ser dominado por el diablo, y se inicia la era de la poscultura. «La posmodernidad ha destruido el mito de que las humanidades humanizan» (p. 20) dice sesudamente Vargas Llosa, y la educación liberal al alcance de todos no ha garantizado el progreso, la paz, la libertad ni la igualdad de oportunidades en las democracias modernas. Steiner se había referido al discurso hablado y escrito como columna vertebral de la conciencia cultural, una palabra que está siendo cada vez más subordinada a la imagen. Así, la cultura del libro a la que se refería Eliot parece ser cada vez más marginal. Como sea, el ensayo de Steiner resulta en un estallido de delirio intelectual, siguiendo a Vargas Llosa.

El tercer ensayo del que viene a ocuparse el escritor peruano es poco anterior al ensayo de Steiner (1967), y se trata de La Société du Spectacle, de Guy Debord, para quien el espectáculo es lo que Marx llamara «alienación» en sus Manuscritos económicos y filosóficos. Para Debord, la alienación ha copado la vida social en la sociedad industrial moderna en la que ha triunfado el capitalismo. La vida ya no se vive, más bien se representa y el consumidor real se convierte en consumidor de ilusiones.

Entre los ensayos que buscan definir los rasgos característicos de la cultura actual, Vargas Llosa escoge el de G. Lipovetsky y J. Serroy, La cultura-mundo. Respuesta a una sociedad desorientada donde se sostiene la entronización de una cultura global, en la que los mercados, la revolución científica y tecnológica trabajan en el eclipse de las fronteras. Esta cultura ha dejado de ser «elitista, erudita y excluyente y se ha convertido en una genuina "cultura de masas"» (p. 27). Lo que busca esta cultura es divertir, hacer posible la evasión fácil, nace con el predominio de la imagen y el sonido sobre la palabra, a través de la pantalla, y el proceso se ha acelerado con la universalización de Internet. Vargas Llosa expresa su desacuerdo con algunos de los puntos expuestos por Lipovetsky y Serroy que le parecen discutibles, como que esta cultura-mundo ha desarrollado un individualismo a nivel planetario; para Vargas Llosa (y no puedo sino apropiarme de su aseveración), lo que hace esta cultura es más bien aborregar al individuo y hacerlo reaccionar de manera gregaria. Además, si bien Lipovetsky y Serroy consideran que la visita a museos y grandes monumentos históricos son muestra de que la que llaman «alta cultura» es aún legítima, en realidad no es más que mero esnobismo desde la perspectiva de Vargas Llosa.

El ensayo con el que Vargas Llosa cierra la suerte de prólogo con la que inicia su libro es el del sociólogo F. Martel, Cultura Mainstream (2011), donde se describe la «cultura de entretenimiento», donde no se habla de ningún libro sino de El código da Vinci, no se habla de pintura, escultura, música, danza clásica, filosofía ni humanidades en general, sino de películas, programas de televisión, videojuegos, mangas, música rock, pop, rap. Vargas Llosa contrapone la cultura del pasado con ese entretenimiento de hoy que Martel describe y con el que simpatiza. La «cultura» es hoy diversión, y lo que no es divertido resulta no ser cultura; lo que vende es bueno, y lo que no conquista al público es malo; el mercado fija hoy el único valor... 
6 Habiendo sentado estas bases y demostrando en qué medida se ha transformado la noción de cultura en el último medio siglo, Vargas Llosa se concentra en la civilización del espectáculo de la que hoy formamos parte: un mundo de entretenimiento en el que la diversión tiene la primacía, un mundo en el que se banaliza la cultura y en el que el periodismo difunde antes que información chisme y escándalo de manera irresponsable. Uno de los factores de esta corriente (si así pudiera llamársela) es el bienestar y la libertad de costumbres que alcanza Occidente tras el duro período de posguerra, y con ellos la multiplicación de industrias de la diversión, tan necesaria para olvidar todo aquello que perturba y angustia; otro factor es la democratización de la cultura que nace de una voluntad altruista pero que termina trivializando la vida cultural puesto que el objetivo es el de llegar al mayor número: cuestión de cantidad antes que de calidad. Para ejemplificar, Vargas Llosa se refiere a la literatura más representativa de esta época: la light; el entorno predominante de lectores que buscan lecturas fáciles no puede alentar a escritores en aventurarse a escribir obras que exijan esfuerzos intelectuales. Hace alusión a la crítica, que en la época de nuestros abuelos tenía un papel central porque lo que hacía era guiar al ciudadano en el juicio de lo que leería y vería, pero que ha llegado a despojarse de todo su valor, y la publicidad está ocupando su lugar. Apunta cómo los modistos parecen tener hoy en día el protagonismo que tenían antes científicos y filósofos y cómo las estrellas de la televisión y los futbolistas tienen la influencia en los gustos y las costumbres que antes tenían los pensadores y teólogos. Los deportes tienen la importancia que sólo en la Antigüedad llegaron a tener, pero con la gran diferencia de que el cultivo del cuerpo se complementaba con el del espíritu y hoy, por lo general, la búsqueda de esta complementariedad ha desaparecido. Advierte que paralelo al fenómeno de masificación el consumo, antes marginal y reducido, de estupefacientes, muchas veces propio de círculos bohemios y artistas, se ha extendido, y poco tiene que ver con la rebeldía contra las normas establecidas (como antaño), sino más bien responde a la búsqueda del placer a la par que de una escapatoria de preocupaciones y responsabilidades.

7 En cuanto a la religión en Occidente, ésta ha sido remplazada en apariencia por el laicismo. En apariencia porque lo que realmente ha sucedido es que las sectas y las prácticas alternativas de diversos cultos se desplazan de una a otra parte del globo y han venido a remplazar a la Iglesia. Y es que, como dice Vargas Llosa, el ser humano en su generalidad no puede prescindir de la religión por la seguridad de trascendencia y el sosiego que ésta procura, y son pocos los que realmente pueden prescindir de ella, remplazándola con la ciencia, la filosofía, la literatura y las artes. En este sentido, la cultura que puede cumplir esta función es la «alta cultura», que enfrenta los problemas y no los elude.

8 En la política, actores y cantantes han llegado a ocupar cargos importantes y esto debido no tanto a sus aptitudes en el campo, sino a su presencia mediática ${ }^{1}$; han venido a eclipsar el lugar que por siglos había ocupado el «intelectual», cuya tímida intervención en la vida política de hoy no tiene repercusiones. Vargas Llosa considera razones válidas para que esto haya sucedido: la simpatía de generaciones de intelectuales con regímenes totalitarios, la ínfima vigencia que tiene el pensamiento en la civilización del espectáculo y la primacía de las imágenes sobre las ideas. Para el autor, son las artes plásticas las primeras en sentar las bases de la cultura del espectáculo, «confiriendo el estatuto de artistas a ilusionistas que ocultan su [...] vacío 
detrás de [...] la supuesta insolencia» (p. 49). Las artes plásticas parecen además haber colaborado en la desaparición de parámetros estéticos.

En cuanto al sexo, la liberación de antiguos prejuicios y tabúes de carácter religioso ha conocido, en contrapartida, la banalización del acto sexual y, a propósito, Vargas Llosa reflexiona sobre el hecho de que con todo y la notable libertad sexual, los crímenes sexuales no han disminuido, sino todo lo contrario. El autor habla de acto sexual como obra de arte, pero esta concepción cabe dentro de un contexto de refinada sensibilidad y no cabe en uno de sexo fácil, expeditivo y promiscuo, que es el que impregna las nuevas generaciones.

La influencia del periodismo en la civilización del espectáculo se revela en ese periodismo que busca entretener informando, de modo que la prensa que conquista grandes públicos no es la seria y de rigor, sino la que se ocupa del chisme, de la vida privada y de la catástrofe.

11 En un apartado posterior, tras la detallada descripción de la civilización del espectáculo en la que vivimos, Vargas Llosa revisa los diferentes significados y matices que ha tenido el término «cultura» en el pasado: a veces ligado a la religión; otras, a la filosofía o al derecho; otras, a la literatura y las artes; y posteriormente, a los descubrimientos científicos. A pesar de que el impulso no fuera idéntico, la cultura siempre había significado un conjunto de disciplinas que implicaba la reivindicación de un patrimonio de ideas, valores y conocimientos, y eran perceptibles los rasgos distintivos de quienes la cultivaban. Hoy, sin embargo, la noción de cultura se ha extendido tanto que se ha esfumado (inevitablemente recuerdo las proféticas palabras de mi profesor de literatura francesa, que solía repetir que la cultura es como la confitura: mientras menos se tiene, más se la esparce...), y, haciendo interrogativa la afirmación de Vargas Llosa: ¿quién es culto donde todos creen serlo? Los antropólogos «establecieron que cultura era la suma de creencias, conocimientos, lenguajes, costumbres, atuendos, usos» (p.66), sus estudios buscaban la comprensión y el respeto de sociedades primitivas, pero con todo y con su buena fe, lo que hicieron fue contribuir no a que todas las culturas merezcan consideración, sino a que todas se equivalgan, y a que se llegue a creer que es colonialista o racista hablar de culturas superiores e inferiores, o de culturas modernas y primitivas. De la misma manera aportaron, al decir de Vargas Llosa, Bajtín y sus seguidores (yo diría más bien: algunos seguidores de Bajtín), con la abolición de la frontera entre cultura e incultura...

En el siguiente apartado el tema central es la educación, o más bien la crisis que en ella impera. Vargas Llosa parte de las violencias perpetradas en una escuela de las afueras de París y la resignación de los profesores ante los cambios impuestos para implantar la seguridad. Son muchos los países en los que, como Francia, el docente y por ende la figura de autoridad, se ha desprestigiado. En Francia, Mayo del 68 colaboró en que así sea; Mayo del 68 impartió la idea de que toda autoridad (siguiendo la definición del diccionario) es sospechosa, y desde entonces, en Francia como en muchos otros países, el prestigio de los maestros desaparece, al igual que las figuras políticas y culturales que ejercen magisterio moral e intelectual, y se los ha confundido con la imagen del represor. Así, la escuela pública, uno de los grandes logros de la Francia republicana, se ha empobrecido y ha puesto en manos de la enseñanza privada la formación de futuros líderes políticos y culturales. Dentro de este contexto, la interpretación importa más que la obra de arte, y el crítico más que el artista, y no la de un crítico cualquiera: la crítica que separa el lenguaje de la realidad, fruto de ciertas teorías postmodernas, 
sobre todo el deconstruccionismo, pues pocos recuerdan ya o leen aún a Lionel Trilling, por ejemplo, para quien la crítica literaria no puede desligarse del quehacer humano. Vargas Llosa vuelve al tema de la educación haciendo una reflexión sobre el ensayo de Trilling entorno a la enseñanza de la literatura, refiriéndose a la dificultad de impartir el verdadero valor de una obra literaria ante un auditorio, cuando ese valor es verdaderamente perpetrable en la intimidad de la lectura.

En el cuarto apartado del ensayo, Vargas Llosa trata el tema del erotismo que, como las artes y la literatura, ha sido destruido por la civilización del espectáculo: el sexo ha sido rebajado «a lo puramente instintivo y natural» (p. 107), se ha acabado con la discreción y el pudor, y este movimiento en Occidente ha exacerbado la represión en este campo en culturas como la islámica. Vargas Llosa define el erotismo como la desanimalización del amor físico cuya función ennoblecedora es la de embellecer el placer físico, y no en vano recuerda que el Eros es el instinto vital y creativo. Pero recuerda también, sirviéndose del caso de la literatura erótica francesa, en el siglo XVIII, que lo erótico desligado del resto de actividades y funciones de la vida del hombre, sucumbe en la monotonía y su desenfreno, como se constata con Sade, acarrea furiosa violencia.

El siguiente apartado se centra en la cultura y la política, cuyos intercambios son inevitables y necesarios en una sociedad abierta, entre otras cosas, para una continua evaluación crítica del quehacer político. En la civilización del espectáculo, claro, no se dan exigencias ni contribuciones de este tipo. Vargas Llosa trae a colación el caso de la dictadura del general Manuel Apolinario en Perú, y subraya una serie de características que desgraciadamente podrían caber en la descripción de algunas pseudo-democracias imperantes hoy en Hispanoamérica, más allá de las «ideologías» políticas que dicen defender. Se refiere a esta época para destacar cómo, establecido el Estado de derecho en 1956, surge un grupo heterogéneo y crítico de personas con ánimos de hacer política, ya en cargos públicos, ya proponiendo alternativas al gobierno desde la oposición; un hecho que poco tiene que ver con la visión que se tiene de la política hoy en día, que ha sido desprestigiada pues es vista por muchos como «actividad mediocre y sucia» (p. 133), y de esto es en mucho responsable el periodismo frívolo y amarillo. Además, el avance tecnológico, en lugar de haber democratizado la información, ha contribuido en despojar de respetabilidad y seriedad el quehacer político. Como dice Vargas Llosa, «el periodismo escandaloso es un perverso hijastro de la cultura de la libertad» (p.135). Más adelante se refiere a la ley y a la percepción que el ciudadano tiene de ésta, sobre todo en los países latinos e hispanos, no como aquello cuya finalidad es el bien común, sino la obra de un poder que sólo busca servirse a sí mismo y que vale más no violentarlo. El ejemplo, nunca mejor elegido del autor, es la piratería de música, películas y libros en Perú (aunque bien sabemos que no se trata de un caso aislado) que no sólo goza de impunidad sino, en muchos casos, hasta de la protección de la policía... Nada más irónico: la piratería bajo la protección de «agentes de la ley»...

El último apartado está dedicado al tema religioso. No solamente se refiere a la fuerza que ha cobrado el islam, sino a la importancia que sigue teniendo la Iglesia católica con todo y los millones de testimonios que han aparecido en muchos países católicos revelando de violación y pedofilia. El escándalo no ha mermado la influencia de la Iglesia católica (cuyo poder se evidencia en la mayoría de los países latinoamericanos), como tampoco ha impedido a la protestante interferir en la enseñanza escolar estadounidense aboliendo en muchos Estados la teoría de Darwin sobre la evolución. Excluyendo la premisa metafísica y teológica de si Dios existe o no, Vargas Llosa se 
preocupa por la función de iglesias y religiones en la vida cultural de los pueblos. En el cristianismo, por ejemplo, la Iglesia favoreció en el Renacimiento el desarrollo de las artes y las letras, pero fue también brutalmente represiva en el dominio de la investigación científica y para con los sospechosos de heterodoxia. El autor recuerda que sólo con la secularizacón la Iglesia fue aceptando una división estricta entre lo espiritual y lo temporal (secularización que, de hecho, se malentendió en diferentes momentos de la historia en los que se buscó extirpar la religión de la sociedad). Vargas Llosa promulga la necesaria preservación del secularismo como «requisito indispensable para la supervivencia y perfeccionamiento de la democracia» (p.176), pero insiste además en la necesidad de la coexistencia (difícil) de laicismo y la prosperidad de una vida espiritual para que una sociedad libre sea posible. No deja de mencionar la oposición que ha mantenido la Iglesia católica contra el capitalismo y señalar cómo el mercado libre, a pesar de haber hecho surgir a las clases medias, nos ha conducido a la degradación de la cultura, en la que artistas mediocres o nulos «pero vistosos y pirotécnicos diestros en la publicidad y la autopromoción [alcanzan] altísimas cotas de popularidad» (p. 181). Sin embargo, afirma que el fracaso y las crisis del sistema capitalista se deben también al desplome de la estructura de carácter ético y el soporte moral que encarna la vida religiosa, a la vez que afirma que la banalización de la religión ha contribuido a provocar la crisis del capitalismo, porque «la frivolidad desarma moralmente a una cultura descreída» (p. 183). Vargas Llosa se opone a la abolición de la enseñanza religiosa en los colegios públicos porque mutilar este patrimonio de la educación de nuevas generaciones significaría entregarlas de lleno a la civilización del espectáculo: frívola, superficial, ignorante y chismosa, pero insiste en que debe tratarse de una enseñanza religiosa objetiva y responsable donde se explique el papel hegemónico del cristianismo en Occidente y su influencia (para bien y para mal) en la historia, la filosofía, el arte y la literatura.

16 La conclusión final de Vargas Llosa llega con un tono un tanto triste: la cultura parece ya no ser la manera de llamar la atención sobre graves problemas que acosan a la sociedad, y parece más bien haberse convertido en el mecanismo de ayuda para olvidarlos y distraer al gran público; parece haberse anclado tanto en la sociedad, que quizás no tenga arreglo, pero quizás por esto mismo caiga por su propio peso o porque carece de uno... Las últimas palabras de Mario Vargas Llosa no son éstas, felizmente, sino las que leyó en 1996 al recibir el Premio de la Paz de los Editores y Libreros alemanes y que comparte con el lector en esta edición: una oda a la literatura y una reflexión sobre su papel en la sociedad, la nuestra y la de todos los tiempos; palabras que entre nombres de poetas y regímenes políticos dejan entrever claramente la posición del autor.

\section{NOTAS}

1. Parece coincidencia, pero esta tarde en la que escribo han puesto en la televisión griega un documental sobre Simone de Beauvoir. Infaliblemente se ven fragmentos de alguna mesa redonda que habría compartido con Sartre y Monti entre otros, y en la que los periodistas 
insisten en conocer el punto de vista de cada uno de ellos sobre la guerra de Argelia. Me doy cuenta de que estamos lejos de todo aquello, hoy, cuando son George Clooney y Sean Penn quienes parecen tener el peso mediático suficiente para dar sus puntos de vista sobre trágicos enfrentamientos bélicos...

\section{AUTORES}

\section{TATIANA ALVARADO TEODORIKA}

Lycée Franco-Bolivien - Investigadora asociada al GRISO-Universidad de Navarra 